\title{
Genetic parameters of body weight and prolificacy in pigeons
}

\author{
Sandrine Mignon-Grasteau*, Léa Lescure, \\ Catherine BEAUMONT \\ Station de recherches avicoles, Institut national de la recherche agronomique, \\ 37380 Nouzilly, France
}

(Received 11 October 1999; accepted 27 April 2000)

\begin{abstract}
Genetic parameters of body weight at weaning and of prolificacy were estimated in three commercial lines of pigeons selected by BLUP (Best Linear Unbiased Prediction) on both traits. The model of analysis took into account the direct genetic effects for both traits and the effect of parental permanent environment for body weight. Depending on the line considered, body weight varied from $556.7 \mathrm{~g}$ to $647.6 \mathrm{~g}$ and prolificacy ranged from 12.5 to 16.8 pigeons weaned per couple of parents per year Heritability of body weight was high, varying between 0.46 and 060 , and permanent environment was responsible for $6 \%$ to $9 \%$ of the total variability On the contrary, prolificacy was poorly heritable $(0.04$ to 0.12$)$ They were highly and negatively correlated $(-0.77$ to -0 82) Body weight showed significant genetic trends in lines $\mathrm{B}$ and $\mathrm{C}$ No significant genetic difference could be observed between males and females for both traits.
\end{abstract}

pigeon / weight / prolificacy / genetic parameters

Résumé - Estimation des paramètres génétiques du poids et de la prolificitê chez le pigeon. Les paramètres génétiques du poids au sevrage et de la prolificité ont été estimés dans trois lignées commerciales de pigeons sélectionnés sur ces deux caractères Le modèle d'analyse prenait en compte les effets génétiques directs pour les deux caractères et l'effet d'environnement permanent du couple parental pour le poids. Suivant la lignée considérée, le poids variait de $556,7 \mathrm{~g}$ à $647,6 \mathrm{~g}$ et la prolificité de 12,5 à 16,8 pigeonneaux sevrés annuellement par couple de parents. L'héritabilité du poids était élevée (de 0,46 à 0,60 selon la lignée) et l'effet d'environnement permanent responsable de $6 \%$ à $9 \%$ de la variabilité totale. A l'opposé, la prolificité était peu héritable $(0,04$ à 0,12$)$. Les deux caractères présentaient une corrélation génétique fortement négative $(-0,77 \mathrm{a}-0,82)$. Une évolution significative de la valeur génétique $a$ été observée pour le poids des lignées $B$ et $C$. Aucune différence génétique significative n'a pu être mise en évidence entre mâles et femelles pour ces deux caractères.

pigeon / poids / prolificité / paramètres génétiques

\footnotetext{
* Correspondence and reprints

E-mail: grasteau@tours.inra.fr
} 


\section{INTRODUCTION}

The pigeon is a species with a moderate economic importance, but its production has recently enhanced due to diversification of poultry products. Moreover, this species presents some interesting biological features. On the contrary to most other domestic species, it is monogamous; couples are stable and prolificacy is low, i.e., 7 to 10 clutches with 1 or 2 squabs per year. Thus the population is structured with full-sib families. Moreover, artificial insemination cannot be used since ovulation is induced by mating. Finally, male and female parents secrete a "crop milk", milky substance used to feed young squabs [12, 15]. Thus in this species, growth is expected to result from the animal's own genes, from the dam's ability to produce large eggs of good quality but also from a parental environmental effect, since both sire and dam contribute to brood eggs and to feed the young squabs.

These specificities make it difficult to estimate genetic parameters of growth and reproductive traits in pigeons for selection purposes. In fact, no estimation of heritability of prolificacy is available yet. Only two studies have estimated heritability of body weight on one single population $[1,6]$ and two studies have estimated the genetic correlation between production and reproduction traits, also on one single population $[9,10]$. Moreover, these studies were performed on a low number of animals (progeny of 72 to 240 couples), and used regression of offspring on mid-parent, or full-sib analysis of covariance. Finally, Aggrey and Cheng $[1,2]$ could not distinguish between direct and maternal effects, which led to an overestimation of heritability.

The aim of this study was thus to estimate genetic parameters of traits of economic importance, i.e. body weight and number of squabs weaned per couple (hereafter denoted prolificacy) on a large population of commercial lines of pigeons. An animal model including a permanent couple effect was fitted in order to distinguish between direct and environmental effects and to take into account the biological characteristics of this species. We also computed phenotypic and genetic trends of these traits in these lines, for the period during which the selection was carried out. Finally, sexual dimorphism (defined as the difference between male and female traits) which has been proved to increase with selection for a higher body weight in other species [11], was also considered here based on the genetic correlation between male and female traits.

\section{MATERIALS AND METHODS}

\subsection{Data set}

Three commercial lines of pigeons were studied. Details on the data files are given in Table I. Animals had been weighed at weaning, r.e., at 4 weeks of age (BW4). The total number of squabs weaned per couple and per year, hereafter called prolificacy (PROL), was also recorded, but not on individuals as pigeon couples are stable. It is of note that components of the total prolificacy, i.e., size of each clutch and number of clutches per couple were not available. Sex, age at weaning ( 27 to 31 days), birth year-season, rearing buildings and size 
Table I. Description of data files used in the analysis.

\begin{tabular}{lccc}
\hline & \multicolumn{3}{c}{ Line } \\
& $\mathrm{A}$ & $\mathrm{B}$ & $\mathrm{C}$ \\
\hline Number of animals in the data file & 10540 & 6461 & 6841 \\
Number of males & 5420 & 3420 & 3580 \\
Number of females & 5120 & 3041 & 3261 \\
Number of couples of parents & 649 & 533 & 542 \\
\hline Number of buildings & 12 & 8 & 8 \\
Number of year-seasons & 33 & 35 & 34 \\
Mean litter size & $1.89 \pm 0.32$ & $1.87 \pm 0.34$ & $1.88 \pm 0.33$ \\
Mean weaning age & $29.3 \pm 1.5$ & $29.3 \pm 1.3$ & $29.3 \pm 1.4$ \\
\hline
\end{tabular}

of the clutch were animals were born ( 1 or 2 pigeons) have also been recorded. The three lines have been selected by BLUP for 10 years on BW4 and PROL. The weighting of BW4 was lower in line A and higher in lines B and C.

\subsection{Choice of the model of analysis}

Significance of fixed effects was tested on both traits using the GLM procedure of SAS ${ }^{\circledR}$ [14]. For BW4, the rearing building, birth year-season, sex and litter size effects were significant and thus taken into account in the analysis. Weaning age was only significant in line $A$, and then fitted in this line only. For PROL, the only significant effect was birth year-season. In fact, this effect indicates the age of the animal and indirectly, the length of the period of reproduction during which prolificacy was recorded.

The log-likelihoods of models (1) to (4) were first computed to determine the most appropriate model of analysis of BW4:

$$
\begin{aligned}
& B W 4_{i \jmath k l m o}=\mu+C S_{\imath}+S_{\jmath}+B_{k}+Y S_{l}+\left(W A_{m}\right)+a_{o}+e_{\imath \jmath k l m o} \\
& \mathrm{BW4}_{\imath \jmath k l m n o}=\mu+C S_{\imath}+S_{\jmath}+B_{k}+Y S_{l}+\left(W A_{m}\right)+c_{n}+a_{o}+e_{\imath \jmath k l m n o} \\
& \mathrm{BW} 4_{\imath \jmath k l m n o}=\mu+C S_{\imath}+S_{\jmath}+B_{k}+Y S_{l}+\left(W A_{m}\right)+m_{n}+a_{o}+e_{\imath \jmath k l m n o} \\
& \mathrm{BW} 4_{\imath \jmath k l m n o}=\mu+C S_{\imath}+S_{\jmath}+B_{k}+Y S_{l}+\left(W A_{m}\right)+c_{n}+m_{n}+a_{o}+e_{\imath \jmath k l m n o}
\end{aligned}
$$

where $\mathrm{BW} 4_{2 j k l m n o}$ was the body weight at 4 weeks of the oth animal, $\mu$ the general mean, $C S_{\imath}$ the fixed effect of the $i$ th level of clutch size, $S_{j}$ the fixed effect of the $j$ th sex, $B_{k}$ the fixed effect of the $k$ th building, $Y S_{l}$ the fixed effect of the lth birth year-season, $W A_{m}$ the fixed effect of the $m$ th age at weaning (fitted only in line A),$c_{n}$ the random effect of permanent environment for the $n$th couple of parents, $m_{n}$ the random genetic effect of the $n$th mother, $a_{o}$ the random genetic effect of the oth animal and $e_{2 j k l m n o}$ the residual corresponding to the oth animal.

The following model (5) was used to analyse PROL:

$$
\mathrm{PROL}_{l o}=\mu+Y S_{l}+a_{o}+e_{l o}
$$


where $\mathrm{PROL}_{l o}$ was the number of squabs weaned per year by the oth animal, $Y S_{l}$ the fixed effect of the $l$ th birth year-season, $a_{o}$ the random genetic effect of the oth animal and $e_{l o}$ the residual corresponding to the oth animal.

\subsection{Estimation of the genetic parameters}

Genetic parameters were estimated with the VCE4 software [13]. Since distribution of prolificacy deviated from normality, a Box-Cox transformation [4] was used to normalise data. It was defined as:

$$
y_{t}=\frac{y^{t}-1}{t y_{g}^{t-1}}
$$

where $t$ was the parameter of the transformation, $y_{t}$ the transformed variable, $y$ the initial variable and $y_{g}$ the geometric mean of $y$. The $t$ parameter was determined as suggested by (5).

We first estimated genetic parameters of BW4 with models (2) to (4) and PROL with model 5 in a multi-trait analysis. In a second step, male and female body weights were distinguished. We could thus estimate heritability in both sexes and genetic correlation between male and female traits in order to know to which extent genes determining these traits in both sexes are common. Model (2) was used in this step.

Finally, we computed the phenotypic and genetic trends for BW4 and PROL in each line. The former was computed as the least squares estimates of year effects. For the latter, individual genetic values for $\mathrm{BW} 4\left(V g_{\mathrm{BW} 4}\right)$ and PROL $\left(V g_{\text {PROL }}\right)$ as well as the permanent environment effect for BW4 $\left(V c_{\mathrm{BW}}\right)$ were obtained with a multivariate BLUP (Best Linear Unbiased Prediction). The PEST software [8] was used with the former estimates of genetic parameters and the models of analysis (2) for BW4 and (5) for PROL. Since generations overlapped, individual genetic values were averaged by year to obtain the trend over time. The significance of phenotypic and genetic evolutions in each line was tested with the "PROC REG" procedure of SAS ${ }^{\circledR}[14]$.

\section{RESULTS}

\subsection{Basic statistics and phenotypic evolutions}

Elementary statistics are given in Table II. Lines $\mathrm{B}$ and $\mathrm{C}$ were heavier than line A, but their prolificacy was lower. Body weight was slightly higher in males than in females, i.e., by $5.4 \%, 6.6 \%$ and $5.3 \%$ in lines $\mathrm{A}, \mathrm{B}$, and $\mathrm{C}$ respectively.

The phenotypic evolutions of BW4 and PROL in lines A, B, and C are presented in Figure 1. They were positive and significant for body weight in each line. For prolificacy, the evolution was significant in all lines: positive in line $\mathrm{A}$ but negative in lines $\mathrm{B}$ and $\mathrm{C}$, i.e., lines for which the evolution of body weight were the most positive. Equations of the phenotypic regressions of $\mathrm{BW} 4$ and PROL on year are given in Table III. 
Table II. Mean \pm standard deviation on weaning weight (BW4) and prolificacy $(\mathrm{PROL}=$ number of squabs weaned per couple and per year).

\begin{tabular}{lccc}
\hline & \multicolumn{3}{c}{ Line } \\
& A & B & C \\
\hline BW4 $(\mathrm{g})$ & $556.7 \pm 65.5$ & $633.2 \pm 95.3$ & $647.6 \pm 83.9$ \\
$\mathrm{BW4}_{m}(\mathrm{~g})$ & $571.3 \pm 65.6$ & $652.2 \pm 97.0$ & $664.0 \pm 83.4$ \\
$\mathrm{BW}_{f}(\mathrm{~g})$ & $541.2 \pm 618$ & $611.8 \pm 88.8$ & $629.7 \pm 80.6$ \\
\hline $\mathrm{PROL}$ & $16.8 \pm 3.2$ & $12.5 \pm 4.2$ & $13.5 \pm 3.9$ \\
$\mathrm{PROL}_{m}$ & $16.8 \pm 3.2$ & $12.5 \pm 4.2$ & $13.5 \pm 3.9$ \\
$\mathrm{PROL}_{f}$ & $16.8 \pm 3.2$ & $12.5 \pm 42$ & $13.5 \pm 3.9$ \\
\hline
\end{tabular}

$m=$ male, $f=$ female.

Table III. Equations of the regression of phenotypic values of BW4 and PROL on year (expressed in phenotypic standard deviations of the trait), and of the regression of couple and direct genetic values of BW4 and PROL on year (expressed in genetic standard deviations of the trait).

\begin{tabular}{lcccccc}
\hline & & \multicolumn{2}{c}{ BW4 } & & \multicolumn{2}{c}{ PROL } \\
\cline { 3 - 4 } \cline { 6 - 7 } & Line & Intercept & $\beta$ & & Intercept & $\beta$ \\
\hline Phenotypic & $\mathrm{A}$ & $7.574 \pm 0.093$ & $0.178 \pm 0.017$ & & $3.776 \pm 0.456$ & $0.272 \pm 0.094$ \\
regression & $\mathrm{B}$ & $6.098 \pm 0.070$ & $0.207 \pm 0.013$ & & $3.220 \pm 0.201$ & $-0.049 \pm 0.042$ \\
& $\mathrm{C}$ & $7.272 \pm 0.087$ & $0.148 \pm 0.016$ & $3.843 \pm 0.098$ & $-0.123 \pm 0.021$ \\
\hline & $\mathrm{A}$ & $-1.496 \pm 0.170$ & $0.218 \pm 0.026$ & - & - \\
Couple & $\mathrm{B}$ & $-0.817 \pm 0.071$ & $0.154 \pm 0.011$ & - & - \\
regression & $\mathrm{C}$ & $-0.813 \pm 0.080$ & $-0.154 \pm 0.012$ & - & - \\
\hline & $\mathrm{A}$ & $0.002 \pm 0.022$ & $0.003 \pm 0.004$ & & $0.0172 \pm 0.0005$ & $-0.0000 \pm 0.0001$ \\
Genetic & $\mathrm{B}$ & $-0.103 \pm 0.036$ & $0.035 \pm 0.006$ & & $0.0213 \pm 0.0005$ & $-0.0007 \pm 0.0001$ \\
regression & $\mathrm{C}$ & $-0.111 \pm 0.026$ & $0.043 \pm 0.004$ & & $0.0107 \pm 00014$ & $-0.0006 \pm 0.0003$ \\
\hline
\end{tabular}

\subsection{Choice of the model of analysis of BW4}

Log-likelihood significantly increased when including the parental environment effect $(+56.3,+60.6$, and +45.0 with the model $(2)$ in comparison with model (1) in lines $\mathrm{A}, \mathrm{B}$, and $\mathrm{C}$ respectively) or the maternal genetic effect $(+56.8,+46.0$, and +19.2 with the model (3) compared to model (1) in lines A, $\mathrm{B}$, and $\mathrm{C}$ respectively) in the model. When taking into account both maternal genetic effect and parental environment effect (model (4)), maternal heritability was estimated as 0 in lines $B$ and $C$. In line A, it was estimated as 0.06 but the log-likelihood did not increase significantly compared to models (2) and (3). 


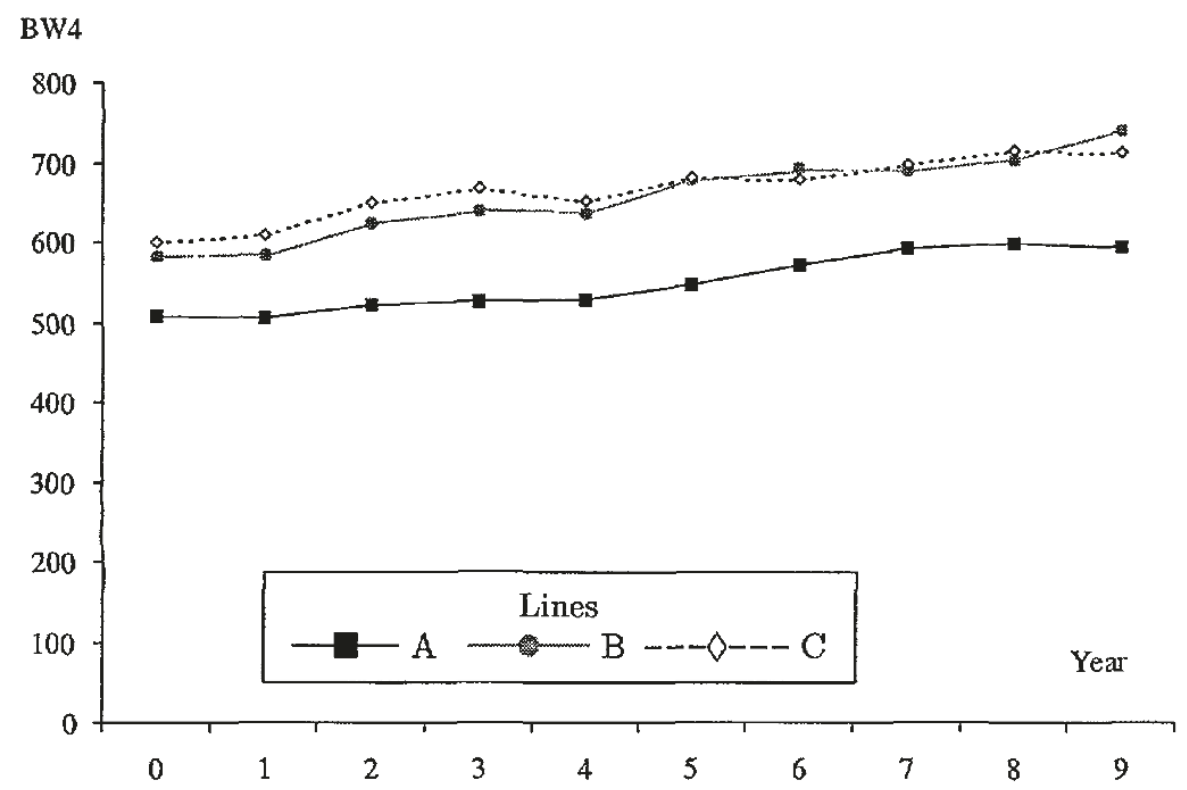

PROL

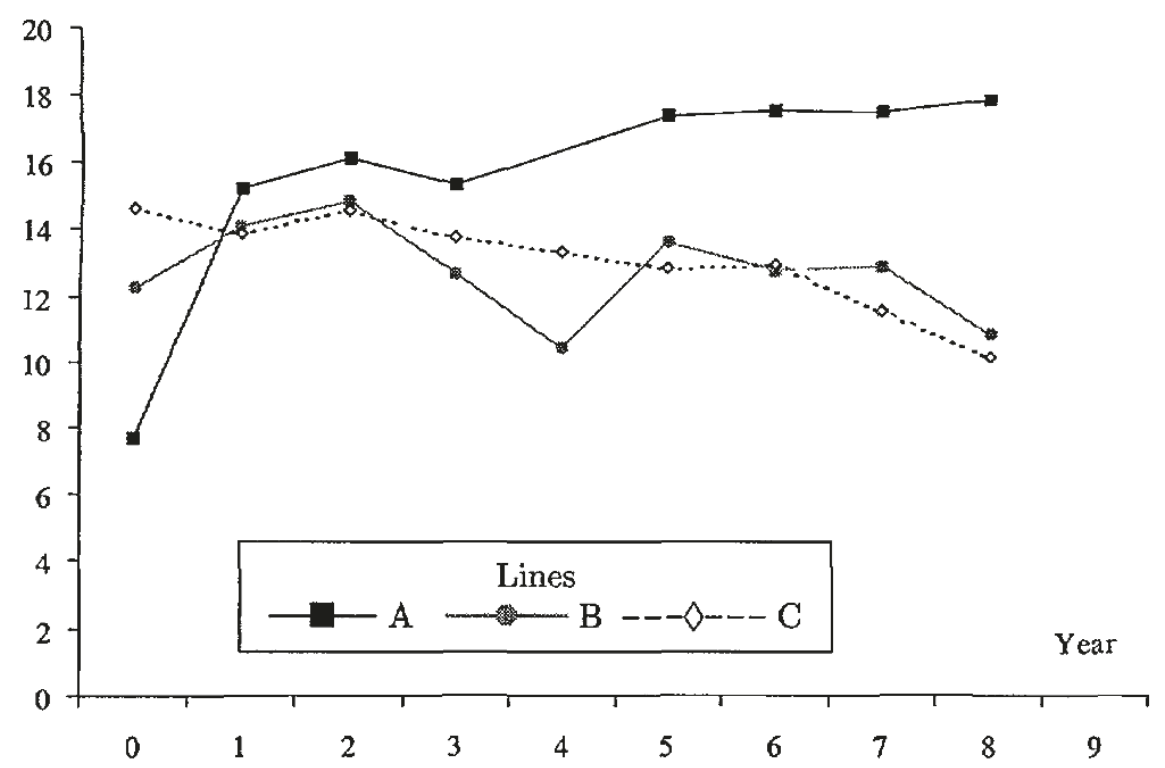

Figure 1. Phenotypic evolution of body weight (BW4) and prolificacy (PROL).

The results presented hereafter for $\mathrm{BW} 4, \mathrm{BW} 4_{m}$, and $\mathrm{BW} 4_{f}$ were thus obtained with model (2).

\subsection{Genetic parameters and genetic trends}

Genetic parameters of BW4 and PROL are given in Table IV. Heritability of body weight was high, with a low influence of parental environment. On 
Table IV. Parameter estimates \pm standard errors $\left(h^{2}:\right.$ heritability; $c^{2}$ : effect of permanent environment of parental couple; $r_{p}$ : phenotypic correlation; $r_{g}$ : genetic correlation) of weaning weight (BW4) and prolificacy (PROL).

\begin{tabular}{|c|c|c|c|}
\hline & \multicolumn{3}{|c|}{ Line } \\
\hline & $\mathrm{A}$ & $\mathrm{B}$ & $\mathrm{C}$ \\
\hline$h^{2}(\mathrm{BW} 4)$ & $0.53 \pm 0.02$ & $0.46 \pm 0.03$ & $0.60 \pm 0.03$ \\
\hline$c^{2}(\mathrm{BW} 4)$ & $0.06 \pm 0.01$ & $0.09 \pm 0.01$ & $0.06 \pm 0.01$ \\
\hline$h^{2}(\mathrm{PROL})$ & $0.04 \pm 0.03$ & $0.08 \pm 0.03$ & $0.12 \pm 0.03$ \\
\hline$r_{p}(\mathrm{BW} 4, \mathrm{PROL})$ & $0.03 \pm 0.05$ & $-0.36 \pm 0.05$ & $-0.32 \pm 0.05$ \\
\hline$r_{g}(\mathrm{BW} 4, \mathrm{PROL})$ & $-0.81 \pm 0.31$ & $-0.82 \pm 0.14$ & $-0.77 \pm 0.11$ \\
\hline
\end{tabular}

the contrary, PROL was poorly heritable. The genetic correlation between both traits was highly negative. The phenotypic correlation between BW4 and PROL was low and negative. The genetic correlation between $\mathrm{BW} 4_{m}$ and $\mathrm{BW} 4_{f}$ was estimated at $1.00,0.98$ and 1.00 for lines $\mathrm{A}, \mathrm{B}$, and $\mathrm{C}$ respectively. Differences of heritability between $\mathrm{BW} 4_{m}$ and $\mathrm{BW} 4_{f}$ were low $(-0.01,0.06$ and 0.05 for lines $\mathrm{A}, \mathrm{B}$ and $\mathrm{C}$ respectively) and non-significant.

The evolutions over time of direct genetic values for weaning weight and prolificacy as well as values for couple effect for weaning weight are given in Figures 2 and 3 respectively. Equations of the regressions on year of the direct genetic values for PROL and BW4, and of the couple values for BW4 are given in Table III. Except for direct genetic values of BW4 and PROL in line A, all of them were significant. The parental environment effect showed a greater variation than the direct genetic effect. It increased in the three lines. Lines $\mathrm{B}$ and $\mathrm{C}$ also showed a marked increase of direct genetic values for weaning weight and a slight decrease of direct genetic value for prolificacy.

\section{DISCUSSION}

\subsection{Choice of the model of analysis}

On the contrary to most of the poultry species, pigeon performances are influenced by several fixed effects. As parents brood and feed the young squabs, growth performances are affected by litter size in addition to parental effects. Buildings are open and, even if conditions are partially controlled, year-season, i.e., climate, influences the performances. Year-season also plays a role on prolificacy in our study since it notably indicates the age of the animal and then the length of the period during which reproduction was recorded.

The biological specificities of the pigeon also made it necessary to fit a maternal genetic or a couple effect to explain body weight at 4 weeks. In a cross fostering experiment, Aggrey and Cheng [1,2] distinguished the preovipositional effect (i.e., before adoption if any), postovipositional effect and the interaction between both effects on BW4. The first included the direct genetic variance but also the maternal effect on size and quality of the egg 


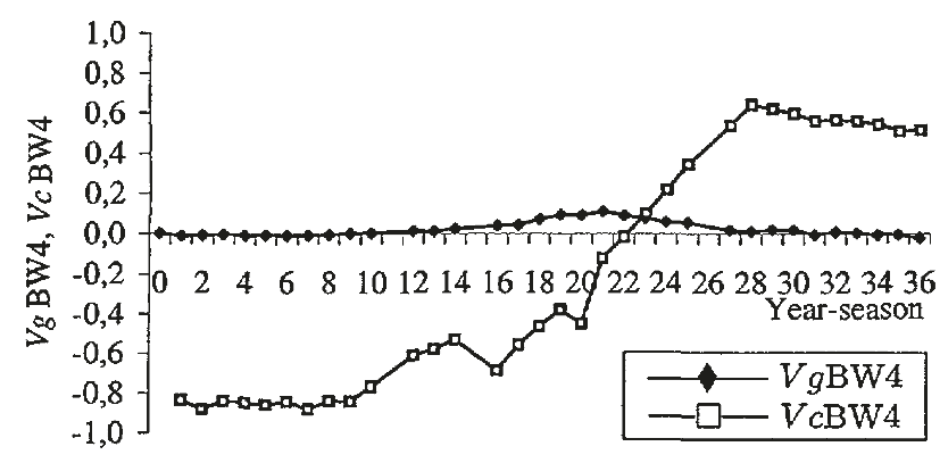

Line A

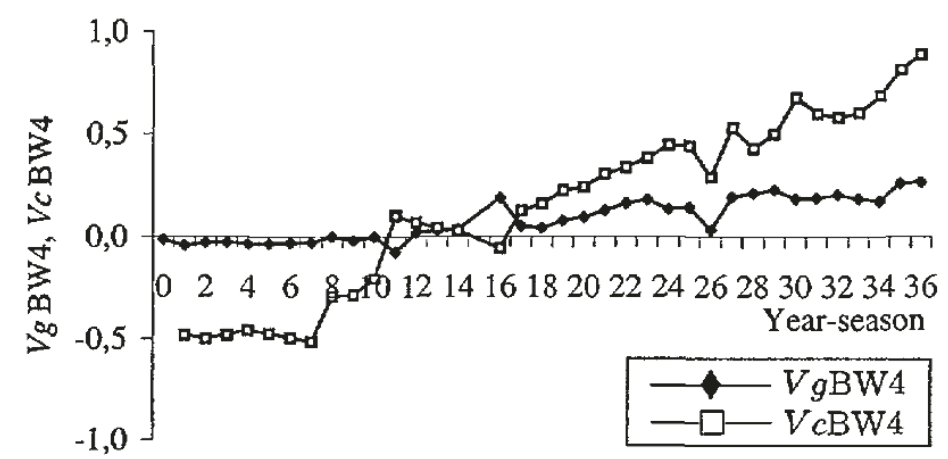

Line B

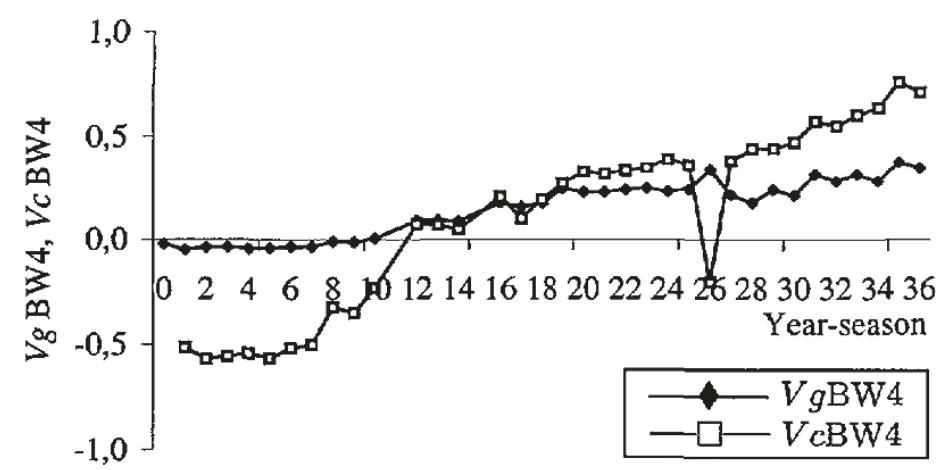

Line C

Figure 2. Evolution over time of the mean genetic value $(V g \mathrm{BW})$ and the mean effect of parent pair envuronment $(V c B W 4)$ on weaning weight, expressed in genetic standard deviations.

and the second the ability of parents to brood eggs and feed the squabs. The preovipositional effect was moderate, but the postovipositional variance was estimated as a negative value and the interaction was high, which showed that the partitioning of the variance was not optimal.

We used an animal model, which allowed to distinguish between the direct genetic effect and other effects, in order to avoid overestimation of heritability. 


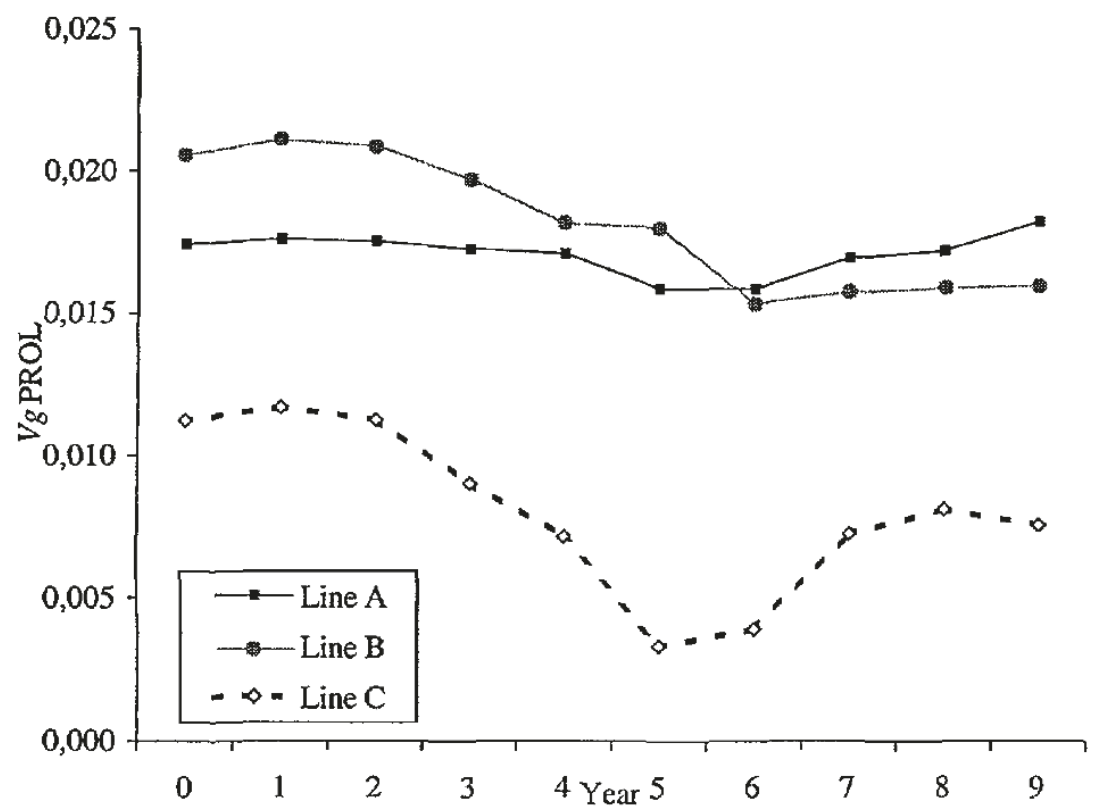

Figure 3. Evolution over time of the mean genetic value for prolificacy ( $V g_{\text {Prol }}$ ) expressed in genetic standard deviations.

In our case, introducing either the maternal genetic effect or the couple environment effect on BW4 significantly increased the log-likelihood. However, it was difficult to distinguish between maternal genetic and environmental effects because their global influence on BW4 was rather low. Fitting both led to inconsistent results, i.e., a zero maternal heritability in lines B and C. This suggested that the permanent effect was more important than the maternal genetic effects. In addition, the correlation between the direct and maternal genetic effects was low, i.e., $0.10,0.20$, and -0.31 for lines $\mathrm{A}, \mathrm{B}$ and $\mathrm{C}$ respectively. These estimates were consistent with those of (3). These authors estimated the correlation between direct and indirect parental effects at 0.14 , using a variance analysis on the same population as in (1), but keeping only progeny of the couples with more than four clutches. Model (2), which moreover did not imply neglecting the father effect on this trait, was thus retained.

\subsection{Estimates of genetic parameters}

\subsubsection{Body weight}

Estimates of heritability of weaning weight in the literature ranged between 0.56 and $0.65[1,6]$. Our estimates tended to be lower. This could be expected since, in these two studies, the genetic variance and the variance of the dam effect on size and quality of the egg were not disentangled. Our estimates of permanent environment effect were low. This was consistent with estimates of the fostering effect obtained by (2) for body weight at 1, 2, and 3 weeks. This low value could be explained by the fact that at weaning age, parents do not 
take much care of the squabs anymore, especially the dam, who is involved in the next clutch (2).

Genetic evolution of body weight was low, but this should be expected since BLUP selection was more dedicated to prolificacy. The trend for the parental environment effect was higher than for direct genetic effects. This could result from the improvement of breeding techniques and in turn from the parent's ability to feed their young. Moreover, some confusion between direct genetic and parental environment effects may have occurred. When comparing results presented in Figure 2, to trends observed when using model (1), we observed that the direct genetic values roughly evolved as the sum of direct and parental value in Figure 2.

\subsubsection{Prolificacy}

No estimate of heritability of prolificacy was available in the literature, but our low estimates were consistent with the slow trend of this trait observed in our lines. This was especially the case for line A, for which the weight accorded to PROL during selection was higher than in lines B and C. Cheng and Yelland [6] also noted that the number of pigeons produced by a couple each year has not progressed since 1940 [6]. It would thus be interesting to decompose this trait into its components (laying rate, fertility, hatchability, survival of squabs, ...) to understand its control. The size of each clutch and the interval between two successive clutches could also be of interest. However, all these data are not yet available. Behaviour traits should also be considered. Since nests are high, animals have to fly to reach them, so that some of the heaviest animals have difficulties reaching the nest, and then laying eggs. However, the lightest animals have a higher laying rate, but are also more nervous and break the eggs more often.

\subsubsection{Sexual dimorphism}

Our estimates of the genetic correlation between male and female body weight were higher than the estimates obtained for Muscovy ducks, chickens or turkeys $[5,11]$. This could be explained by the lower sexual dimorphism of ihe pigeon. It can be concluded from our estimates that growth of male and emale squabs are controlled by the same genes.

\subsubsection{Genetic correlation between BW4 and PROL}

The genetic opposition between production and reproduction traits was ound in pigeons $[9,10]$ as in other poultry species [7]. The opposite evolutions of genetic values of BW4 and PROL in our lines is coherent with the highly regative genetic correlation, which was itself consistent with the phenotypic sorrelation between BW4 and PROL. This could explain why, despite the Jrogress obtained on body weight of pigeons, the annual productivity of a souple (in $\mathrm{kg}$ of squabs per year) did not vary [3]. This high correlation could ave resulted from the model of analysis of BW4 which included the effect of lutch size and thus of PROL on body weight. But, even when clutch size was 
not included in the model, the genetic correlation between BW4 and PROL remained nearly constant. Behaviour characteristics described higher could be an explanation to this highly negative correlation.

For selection, it implies that it should be better to cross specialised lines for a high body weight or a high prolificacy than to select on both traits in the same line. Another possibility to improve performances would be to try to reduce weaning age and thus slaughter age and the interval between two successive clutches, but genetic correlation between weaning age at a given BW4 and prolificacy is needed in order to know to what extent this approach may help to increase the number of clutches laid by a couple in a given period.

\section{CONCLUSION}

Our estimates showed that body weight at weaning in pigeons is highly heritable and thus easy to select for. On the contrary, the low heritability of prolificacy, along with the high negative correlation between the two traits make it very difficult to improve the final criteria of productivity, i.e., total weight of squabs weaned per couple. It would probably be necessary to decompose the number of squabs into more elementary components such as the number of eggs or survival, to progress in this way.

\section{REFERENCES}

[1] Aggrey S.E., Cheng KM., Estimation of genetic parameters for body weight traits in squab pigeons, Genet. Sel. Evol. 24 (1992) 553-559.

[2] Aggrey S.E., Cheng K.M., Genetic and posthatch parental influences on growth in pigeon squabs, J. Hered. 84 (1993) 184-187.

[3] Aggrey S.E., Cheng K.M., Genetic correlation between genetic and parental effects on growth in pigeon squabs, J. Hered. 86 (1995) 70-72.

[4] Box G.E., Cox D.R., An analysis of transformations, J. Hered. 26 (1964) 211-243.

[5] Chapuis H., Ducrocq V., Tixier-Boichard M., Delabrosse Y, Multivariate restricted maximum likelihood estimation of genetic parameters for production traits in three turkey selected strains, Genet. Sel. Evol. 28 (1996) 197-215.

[6] Cheng K.M., Yelland G., Factors affecting squab bodyweight and the number of squabs produced in a year, in. 18th World's Poultry Congress, Nagoya, 4-9 September 1988, Japan Poultry Science Association, pp. 586-588.

[7] Fairfull R., Gowe R.S., Genetics of egg production in chickens, in: Crawford R.D. (Ed.), Poultry breeding and genetics, Elsevier, Amsterdam, 1990, pp. 705-760.

[8] Groeneveld E., PEST User's manual, 1990

[9] Meleg I., Horn P., Genotypic and phenotypic correlations between growth and reproductive traits in meat-type pigeons, in: 9th European Poultry Conference, Glasgow, 7-12 August 1994, World's Poultry Science Association, London, pp. 343-344.

[10] Meleg I., Horn P., Genetic and phenotypic correlations between growth and reproductive traits in meat-type pigeons, Arch. Geflugelkd. 62 (1998) 86-88.

[11] Mignon-Grasteau S , Beaumont C , Poivey J.P., de Rochambeau H., Estimation of the genetic parameters of sexual dimorphism of body weight in "label" chickens and muscovy ducks, Genet. Sel. Evol. 30 (1998) 481-491. 
[12] Nepote K.H., Pigeons as laboratory animals, Poult. Avian Biol. Rev. 10 (1999) 109-115.

[13] Neumaier A., Groeneveld E., Restricted maximum likelihood estimation of covariances in sparse linear models, Genet. Sel. Evol. 30 (1998) 3-26.

[14] $\mathrm{SAS}^{\circledR}$ Institute Inc., $\mathrm{SAS}^{\circledR} / \mathrm{STAT}^{\circledR}$ User's guide, version 6, 4th edn., Cary NC: SAS ${ }^{\circledR}$ Institute Inc., 1989.

[15] Sauveur B , Reproduction femelle - Couvaison, in: Reproduction des volailles et production d'œufs, INRA Versailles, 1989, pp. 77-87. 